\title{
Awareness of Lifestyle and Independence of Parasite Singles
}

\author{
Hyun-Ju Kim ${ }^{1}$, Jeong-Moo Hurh ${ }^{2}$ \\ ${ }^{1}$ Part-time Instructor, Dep. of Early Childhood Education, Chungcheong University, Korea, \\ hyunju1204@hanmail.net \\ ${ }^{2}$ Professor, Dep. of Early Childhood Education, Korea National University of Transportation, \\ Korea,jmhuh@ut.ac.kr \\ Corresponding Author: Jeong-Moo Hurh
}

\begin{abstract}
There is an increasing trend of parasite singles in their 30s who are not rushing to get married, staying at their parents' house, enjoying the services provided by their parents, and relying their freedom and daily living on their parents. The increase in the number of parasite single can cause social problems not only at the individual family level but also to the overall family system. The purpose of this study is to analyze the lifestyles of parasite singles and their perceptions of independence towards becoming an independent member of the family. A survey was conducted among 30 office workers in their 30 s who live in Seoul and work at the headquarters of large corporations, single and have a college, education and are living with their parents at their parents' house. The survey was conducted for two months from May 2021 using the questionnaire developed by the researcher. The questionnaire was distributed and collected through postal survey. For the data analysis method, frequency analysis was applied. As a result of analyzing the perceptions of parasite singles on independence, it was found that there are many parasite singles who think that they are not yet financially independent even after graduating from school and finding a job. Parasite singles who lived with their parents unilaterally received services from their parents, and were almost exempted from sharing their roles at home. Parents' satisfaction with living with parasite singles was higher. In conclusion, it is suggested that preparing the foundation for independence in response to economic difficulties will be an important task because there is a possibility that the foundation of living will collapse when an economically difficult situation arrives.
\end{abstract}

Keywords: Parasite Single, Parents, Lifestyle, Economic, Independence

\section{Introduction}

The average age of first marriage for unmarried men and women in 2020 was $33.2 \%$ for men and $30.8 \%$ for women, increasing the unmarried rate among the youth population[1]. In 2018, $41.2 \%$ of single men and $54.7 \%$ of single women did not intend to marry, and the trend to avoid marriage is expected to gradually increase[2]. As unmarried men and women prefer to remain single without getting married, the number of parasite singles in their 30s who are dependent on their parents for freedom and daily life while staying at their parents' house without rushing to get married and enjoying the services provided by their parents is on the rise. It can be said that the trend toward higher education and the economic affluence of the parents' generation made it possible to provide long-term aid to their adult children even after graduating from college. Recently, according to the aggravation of the unemployment crisis, while preparing for employment, even adult children over the age of 30 are allowed to stay with their parents and a social trend has been formed in which long-term assistance is

Received: July 08, 2021; $1^{\text {st }}$ Review Result: August 25, 2021; $2^{\text {nd }}$ Review Result: October 11, 2021 Accepted: November 30, 2021 
taken for granted.

The current parent generation of parasite singles in their 30s was born in the late 1960s and married in the late 1980s. These parents' generation experienced affluence that they did not experience in their youth, and they are realizing the affluence by giving more aid to their children. It became possible for one or two children who were brought up with sufficient consideration according to the trend of low birth rate to continue to receive support from their parents into adulthood.

However, volunteering for children as an expression of affection and expectation resulted in allowing the children's generation to become more self-reliant. It can be assumed that the lifestyle of unmarried singles in the high-educated young people of the urban middle class has emerged as a result of a combination of the simultaneous group between the generation of parents who want to give and the generation of children who say that it is natural to receive.

In the process of becoming an adult, the process of a child becoming independent from their parents' economy has an important meaning. This is because financial independence is an important step in becoming an adult. Economic self-reliance begins slowly while the child stays in the parent's home and is eventually completed by having his or her own economy, completely separate from the parent's economy. The transition from adolescence to adulthood is a time of trial and error to adapt to professional life, and it is also a stage of preparation for forming a family. The material and financial aid and emotional support received from parents during this period are important conditions for a smooth adulthood.

A child becomes an adult only when he or she achieves complete independence through the process of gradually becoming financially independent while living with their parents. The issue of how old parents should raise their children is not uniform, but varies according to the times and social circumstances. This is because the status and role of children in the family differs depending on the family system. It is the responsibility of the parent generation to help parasite singles become economically and emotionally independent and have social rights and responsibilities. This is because it is an important process for unmarried singles to become adults, freeing them from dependence on their parents. Therefore, the increase in the number of parasitic singles dependent on parents is significant because it can cause social problems not only at the individual family level but also at the family system as a whole.

There is a need for research on how young people can become economically and emotionally independent and become adults who have social rights and responsibilities. Being economically independent is an important process for becoming an adult, by which one can take responsibility for oneself and have the awareness and means to fully participate as a member of the society. In general, as society becomes more prosperous, interest in economic aspects that underpinned human life tends to decrease. Therefore, in understanding the parent-child relationship, several aspects must be considered, but the economic relationship that supports the dependent-dependent relationship is an important aspect.

The purpose of this study is to investigate the lifestyles and perceptions of independence of parasite single dependent on parents, and to find a way of indepedence that can design a life based on the analysis results.

\section{Theoretical Background}

There are many aspects to consider in understanding the parent-child relationship, but the material and economic relationship that supports the dependent-dependent relationship can be seen as an important aspect. This is because, in the process of becoming an adult, the process of a child becoming independent from their parents' economy has an important meaning. Financial independence is an important step toward becoming an adult. Economic self-reliance begins slowly while the child stays in the parent's home and is eventually completed by having his or her own economy, completely separated 
from the parent's economy. The transition from adolescence to adulthood is a time of trial and error to adapt to professional life, and it is also a stage of preparation for forming a family. The material and financial aid and emotional support received from parents during this period are important conditions for a smooth adulthood.

An important factor in understanding the parent-child relationship from an economic point of view is that the income between parents and children changes, respectively. It can be seen that the parent-child exchange relationship shows diversity depending on the age difference, income level, and the shape of the wage curve. In general, children are considered dependent on their parents until they reach adulthood, and parents provide for them. During this period, the parents' economic power is overwhelmingly strong, and they are supported and protected by that power. Children gradually begin to walk the path of self-reliance, partly freeing themselves from their parents' support. When parents lose their financial and physical strength as they get older, the parent-child relationship is reversed. From now on, the parent-child support relationship begins, in which the child supports the parent. However, it is difficult to clearly define the economic relationship between parents and children in the transition period from adolescence to adulthood. Since this period is a transition period in the economic relationship between parents and children, it is in a transitional state of being half dependent on parents and half independent. This is because the reality is that until the children get married and start their own family, they depend on their parents if they are having financial difficulties.

In the past, it can be said that some of the total population were single. If singleness due to deficit factors, such as not getting married to take care of family members or taking responsibility for family livelihood on behalf of parents, was predominant in the past[3], in modern society, the difference is that the number of parasite singles dependent on parents is increasing.

Previous studies[4-6] point out that the trend of late marriage due to women's high education level and active entry into the economic market is leading to a low fertility problem. As an example, according to the research result of Lee Ji-hyeon[3], an important factor is that the period of adolescence spent without income activities due to the delay in entry into the labor market because of the increase in individual human capital investment is considered as an important factor. The research results of Kim Ran-young[7] reported that the rise of women's economic status is acting as a factor delaying the marriage decision as high-educated women are newly appearing in the labor market.

The increase in marriage delay and late marriage inevitably entails an increase in the number of adults living dependent on their parents during the preparation period for marriage. It is not only derived from the low fertility problem, but also can bring a new phenomenon of increase in dependence in the relationship between parents and children, so it is necessary to analyze how parental dependence affects late marriage. Since the tendency of late marriage is influenced by each individual's experiences and various environments[8], in order to accurately analyze the marriage delay process, it is necessary to understand the diversity, activity and uniqueness of each individual's experiences. It is necessary to find out the factors affecting the marriage intention of unmarried women, and as a result, a policy to increase the marriage rate and increase the fertility rate is urgently prepared and promoted in earnest. As attitude toward marriage is influenced by personal resources, family, and social environment[9], it is necessary to understand the marriage intention of unmarried adults at the individual level, in interactions with various environments surrounding the individual, and at the government level. Policy support should be considered in an integrated manner.

In general, parasite single it refers to young single people in their late 20 s to under 40 who are financially dependent on their parents while graduating from school and not looking for a job or finding a job even though they have reached the age of self-reliance[10]. The increase in the number of single has a negative impact on themselves and their families, and has emerged as a serious social problem in that it can cause significant socio-economic losses. In the case of parasite single who are dependent on their parents, it is also reported that there is a strong tendency like the limited class who do not enter the 
labor market while living in the home of their parents who can be economically dependent[11].

The increase in parasite single is pointed out as a social problem causing significant socioeconomic loss. It exacerbates the problem of low fertility by causing an increase in the overall marriage age and an increase in the unmarried population. Due to the existence of economically dependent parents, it has been reported that there is a strong tendency like the limited class, who do not enter the labor market while living with their parents until they find a job that they consider suitable[10][12].

It is predicted that the existence of parasite singles can have a negative impact on the parent-child relationship as well as the problems that affect the society as a whole. From a parent's point of view, the existence of an unmarried, economically dependent adult children despite becoming an adult acts as an economic burden, is predicted to cause deepening of family conflict and weakening of family function as a psychological stress[13]. It can a negative impact not only on the parents' financial burden, but also on the psychological and emotional aspects of parents[14].

Young adult's employment behavior is greatly affected by family demographic conditions such as family composition, cohabitation with parents, and separation. It is said that when children start is closely related to the question of whether or not to live with their parents. Living with parents has a similar meaning to unemployment insurance for children. If the market's wages are too low, they do not start working while living with their parents. However, once the wage reaches a certain level, they continue to live together with their parents and start working. And when wages rise further, they separate from their parents. In the end, living with parents is indirect assistance, such as shared use of housing or facilities, even if you do not receive direct money. It is only because of it that you can have the freedom to choose a job with better conditions.

\section{Research Method}

In this study, a quantitative research method through questionnaire survey was applied. The perception of lifestyle and independence was investigated among high-educated parasite singles in their 30 s and their parents living in large cities. This study was conducted among 35 university graduates who are single, living with their parents in their parents' office workers in their 30s who live in Seoul and work at the headquarters of a large corporation. As a research tool, a questionnaire developed by the researcher after facial validity verification by two experts was used. Thirty-two copies were recovered after investigating for two months from May 2021. Excluding two inappropriate copies, thirty copies were analyzed. As the data analysis method, frequency analysis was applied. Among the 30 s there are 18 males and 12 females. The age distribution of males in their 30s is six people aged 30-33, eight people 34-36 years old, and four people 37-39 years old. The age distribution of women in their 30s is six patients aged 30-33 years, four patients aged 34-36 years, and two patients aged 37-39 years. Among the $50 \mathrm{~s}$, the parental generation, there are 30 males and 30 females. Frequency analysis was performed on the collected data.

The research was conducted with approval from the Research Ethics Review Board (IRB) of the researcher's affiliated institution. During the study, the purpose, method, and process of the study were explained in detail to the study participants, and the study was conducted among those who voluntarily expressed their intention to participate in the study. When analyzing research data and stating the results, personal information was encoded and recorded. Efforts were made not to interfere with the researcher's subjectivity and prejudice in interpreting the research results. Even if parents do not have enough financial resources, if parents and children live together, they can receive indirect assistance from their parents, extending the period of investment in themselves. It is said that the fewer the brothers, the easier it will be. 


\section{Results and Interpretation}

[Table 1] and [Table 2] show the results of a survey of the satisfaction of parasite singles and parents who live together on the parents' house.

[Table 1] Satisfaction of Parasite Singles Living with their Parents

\begin{tabular}{c|cccc}
\hline Epec. & Satisfied & I do not know & Dissatisfaction & Total \\
Male & $9(50.0)$ & $7(38.8)$ & $2(11.2)$ & $18(60.0)$ \\
Female & $7(58.3)$ & $3(25.1)$ & $2(16.6)$ & $12(40.0)$ \\
Total & $16(53.3)$ & $10(33.3)$ & $4(13.4)$ & $30(100.0)$ \\
\hline
\end{tabular}

[Table 2] Parents' Satisfaction with Living with their Parasite Single Adult Children

\begin{tabular}{|c|c|c|c|c|c|}
\hline & Spec. & Satisfied & I do not know & Dissatisfaction & Total \\
\hline \multirow{3}{*}{$\begin{array}{c}50 \text { 's } \\
\text { Male }\end{array}$} & Living with son & $11(61.1)$ & $6(33.4)$ & $1(5.5)$ & $18(60.0)$ \\
\hline & Living with daughter & $9(75.0)$ & $3(25.0)$ & $-(0.0)$ & $12(40.0)$ \\
\hline & Total & $20(66.6)$ & $9(30.1)$ & $1(3.3)$ & $30(100.0)$ \\
\hline \multirow{3}{*}{$\begin{array}{c}50 \text { 's } \\
\text { Female }\end{array}$} & Living with son & $10(55.5)$ & $7(39.0)$ & $1(5.5)$ & $18(60.0)$ \\
\hline & Living with daughter & $9(75.0)$ & $2(16.6)$ & $1(8.4)$ & $12(40.0)$ \\
\hline & Total & $19(63.3)$ & $9(30.0)$ & $2(6.7)$ & $30(100.0)$ \\
\hline
\end{tabular}

According to [Table 1] and [Table 2], it was found that the satisfaction of parents who are service providers to their parasite single adult children was higher. In the case of parasite single in their 30s, about half answered that they were 'satisfied', whereas in their 50s, the parents' generation, more than $60 \%$ were satisfied with living together, indicating higher satisfaction with living together than the adult children's generation. There are gender differences here. The relatively high satisfaction with cohabitation is the case of fathers living with their daughters. Satisfaction with living together is high overall, but $70 \%$ of both parents are satisfied with living with their daughter.

One of the reasons for choosing adult children cohabitation for parasite singles is that they are the beneficiaries of domestic services. [Table 3] shows the results of a survey on how parasite singles are in charge of the housework around them.

[Table 3] In Charge of Housework Around

\begin{tabular}{cccccc}
\hline Spec. & Both parents do it & Most parents do it & Do it myself & $\begin{array}{c}\text { Other than parents } \\
\text { people do }\end{array}$ & Total \\
\hline Male & $4(22.3)$ & $6(33.3)$ & $7(38.9)$ & $1(5.5)$ & $18(60.0)$ \\
Female & $2(16.6)$ & $6(50.0)$ & $4(33.4)$ & $-(0.0)$ & $12(40.0)$ \\
Total & $6(20.0)$ & $12(40.0)$ & $11(36.7)$ & $1(3.3)$ & $30(100.0)$ \\
\hline
\end{tabular}

According to [Table 3], it can be seen that most of the housework around both men and women are 
left to their parents. In the case of those in their 30s living with their parents, the combined results of the two responses, 'Both parents do it' and 'Most parents do it', account for about $60 \%$. This dependent communal state can be seen as an important factor in making parasite singles feel comfortable living with their parents rather than living independently.

In addition, the results of a survey on how much sharing the housework role while living with parents are shown in [Table 4].

[Table 4] Degree of Sharing the Housework Role

\begin{tabular}{rccccc}
\hline Spec. & Almost share & Share a little & $\begin{array}{c}\text { Almost } \\
\text { do not share }\end{array}$ & Not at all & Total \\
\hline Male & $-(0.0)$ & $7(38.9)$ & $1(5.5)$ & $10(55.6)$ & $18(60.0)$ \\
Female & $1(8.3)$ & $7(58.3)$ & $-(0.0)$ & $4(33.4)$ & $12(40.0)$ \\
Total & $1(3.3)$ & $14(46.7)$ & $1(3.3)$ & $14(46.7)$ & $30(100.0)$ \\
\hline
\end{tabular}

According to [Table 4], both men and women 'share a little' (46.7\%) and 'not at all' (46.7\%) with regard to housework role, indicating that the share of housework among parasite single adult children is low. When looking at the differences between men and women, it can be seen that the share ratio is higher for women than for men. In general, since most of the housework is the role of women, it can be seen that women who are daughters share more than men who are sons, as women naturally share. The reproduction of this gender division of labor is judged to be derived from the fact that the service provider is only the mother. The structure in which both men and women leave the housework to their mother is to affirm women as the person in charge of housework, and from the point of view of a daughter of the same sex, it is judged that this is because they implicitly acknowledge that when the mother does not do it, she is expected to do it. It can be seen that parasite single adult children are unilaterally receiving services from their parents and are almost exempted from sharing the housework role in family life.

How they use their income is important in knowing the economic position of parasite single dependent on their parents. This is because if parents are poor, they expect their adult children to contribute to the household, and if they have economic power, they will not expect from them. The economic pressure on adult children varies according to the level of economic power of the parents. [Table 5] shows the opinion of parents in their 50s on how to use their parasite single adult children's income.

[Table 5] How Parents Think About How Their Parasite Single Adult Children Use Their Income

\begin{tabular}{cccc}
\hline Spec. & $\begin{array}{c}\text { Left to their freedom because it } \\
\text { belongs to the adult children }\end{array}$ & Parents should manage it & Total \\
\hline Adult child is son & $12(66.6)$ & $6(33.4)$ & $18(60.0)$ \\
Adult child is daughter & $8(66.7)$ & $4(33.3)$ & $12(40.0)$ \\
Total & $20(66.7)$ & $10(33.3)$ & $30(100.0)$ \\
\hline
\end{tabular}

According to [Table 5], 66.7\% of the respondents who said that their parasite single adult children's income should be, and $33.3 \%$ of the responded that 'parents should manage it'. For parents, working adult children are regarded as independent economic agents, and a certain line is drawn in the economic 
relationship between parents and adult children.

In the case of students having part-time jobs, it may be natural to use them for the sake of earning pocket money, but if they are earning a stable income, how they do it is important. In this regard, the results of a survey on how parasite singles use their monthly wages are shown in [Table 6].

[Table 6] Salary Usage of Parasite Singles

\begin{tabular}{|c|c|c|c|c|}
\hline \multirow{2}{*}{ Spec. } & Give it to parents & Giving some to parents & Manage myself & Total \\
\hline & $-(0.0)$ & $9(30.0)$ & $21(70.0)$ & $30(100.0)$ \\
\hline
\end{tabular}

According to [Table 6], 70\% of the respondents answered that they are themselves, followed by about $30 \%$ of the responses giving some to their parents. The biggest change is that adult children who are working in the past by themselves, unlike the ones who gave their parents their salary and received allowances.

Although economic independence is an important milestone towards adulthood, there is no consensus on the age at which one becomes financially independence. In this regard, [Table 7] shows the results of a survey of the parents-dependent parasite singles about their thoughts on economic independence.

[Table 7] Thoughts on the Economic Independence of Parasite Singles

\begin{tabular}{|c|c|c|c|c|}
\hline & Spec. & Independence & Dependence & Total \\
\hline \multirow{4}{*}{ Male } & 30-33's & $1(16.7)$ & $5(83.3)$ & $6(33.3)$ \\
\hline & 34-36's & $6(75.0)$ & $2(25.0)$ & $8(44.4)$ \\
\hline & 37-39's & $4(100.0)$ & $-(0.0)$ & $4(22.3)$ \\
\hline & Total & $11(61.1)$ & $7(38.9)$ & $18(100.0)$ \\
\hline \multirow{4}{*}{ Female } & 30-33's & $1(16.7)$ & $5(83.3)$ & $6(50.0)$ \\
\hline & 34-36's & $2(50.0)$ & $2(50.0)$ & $4(33.3)$ \\
\hline & 37-39's & $1(50.0)$ & $1(50.0)$ & $2(16.7)$ \\
\hline & Total & $4(33.3)$ & $8(66.7)$ & $12(100.0)$ \\
\hline
\end{tabular}

According to [Table 7], males responded that their 'dependence' was high(83.3) until the age of 33, but $75 \%$ at the age of $34-36$ and $100 \%$ at the age of 37-39 answered that they were independent. In the case of parasite single men, it can be seen that the awareness of independence increases with the increase of age. However, in the case of women, as a whole, the ratio of 'dependence' was $66.7 \%$, indicating that the perception of dependence on parents is relatively higher than that of men. Women with a high awareness of dependence, that the awareness of independence does not increase significantly with the increase of age. The difference in the perception of independence between men and women can be attributed to the fact that the income gap between men and women has widened since their mid-30s, and the income of women is relatively lower than that of men. In the case of men, their income increases as their age increases, and the possibility of economic independence is expanding, whereas in the case of women, the increase in income is relatively low, so it can be seen that independence from parental dependence is delayed. 


\section{Discussion}

In European and American societies where the marital system is strict, when children reach a certain age (18-20 years old), most of them leave their parents' house and live alone or start living with friends as a kind of rite of passage in the process of becoming an adult. However, in Korea, where the immediate family system is institutionalized, the couple family system has become common, but the reality is that the number of parasite singles staying with their parents even after they become adults is increasing. There are many higher education institutions within the commuting area from home, and for young adult in the metropolitan area who do not necessarily need to travel to go to school, living with their parents can be seen as continuing for a while while attending school and even after becoming an adult. Many of them are expected to stay with their parents' families after graduation and finding a job. In the case of women, it is even more so. When an adult children gets married, they will need to leave their parents' house, but as the marriage age is getting lower in recent years, it can be seen that young adult are continuing their lives as members of their parents' families through the unmarried period in their 30s.

The phenomenon of parasite singles has recently been extended to the late $30 \mathrm{~s}$. When they reach their 30 s, their income increases, especially for men, and will exceed their parents' oncome. This is because parents enter pension life. Children add a certain amount of money to the household. Parents and children living together are creating a certain reciprocal relationship. There are many types of men who continue to live with their parents instead of getting married and are looked after by those around them instead of taking on a part of the economy. There are many types of women who share the housework while being protected by their parents or are deeply emotionally related to their parents by being the talker of their mothers. Unmarried people in their 30s are creating an economic joint relationship with their parents and an emotional joint relationship as a conversation partner.

As a result of analyzing the lifestyles of parasite singles, it is clear that parasite singles living with their parents are more economically comfortable than those who are separated. If they live with their parents, there are no housing or essential expenses, so that is enough for personal expenses. In some cases, parents may exempt their adult children from contributing to the household because their salary is small or there are various expenses in the early days of their adult children's employment. The income of adult children added to the household is not used for living expenses in many cases, and it is judged that most of them are saved in the name of the adult children for their wedding expenses. Therefore, it can be seen that the economic relationship between parent and adult child tends to give priority to sufficient preparation for the adult children's independence rather than a rational exchange relationship.

As a result of analyzing the perceptions of parasite singles on independence, there are many parasite singles who think that they are not financially independent even after graduating from school and finding a job. The response that they are not economically independent is more prominent among women than among men. For women, it is estimated that the higher the parents' income, the less economically independent they are. For parasite single adult children who depend on their parents for a large part of their daily expenses such as food and housing, they cannot be considered economically independent. The reason why parasite single adult children who do not need to put their income under the management of their parents and who use them as they think are not financially independent is that their entire life is under the protection of their parents.

There are no societal standards today about when children must leave their parents' homes. Social norms that encourage children's independence are also weak. In the case of women, it can be seen that it is weaker. As this situation develops, the number of young people staying with their parents is increasing.

In the past, children have shared some form of economic role within the family. Helping parents has traditionally been an important role for children. In developing countries, children are still an important workforce. However, as a result of industrialization, as the employer's family took up the majority, the 
production function of the home was reduced and expanded to a place of consumption. Although the number of dual-income households increased, the time spent on housework by children did not increase. This situation continues not only in childhood, but also in adolescence and beyond.

\section{Conclusions}

Although the norm of being economically independent when reaching adulthood is supported by the majority of people, nevertheless, various forms of aid are provided to both parents and adult children at the actual level of behavior. For parents, the independence of their adult children is a matter of freedom from the obligation of support and comfort, but it is a problem that involves a conflict between values that they want to keep their adult children close for a certain period of time if possible. For parasite singles, independence from their parents is the gain of freedom and privacy, but at the cost of losing economic and spiritual protection. The reason why parasite singles do not become independent from their parents and stay at their parents' homes is because of the benefits such as free housing, freedom from household responsibilities, and being able to receive protection from their parents.

The problem here is that the life course of parasite singles delays the acquisition of roles and responsibilities as adults. Parasite singles living with their parents are freed from the responsibility of communal living and are in a position to receive services unilaterally. Considering the phenomenon in which their standard of living is determined by their parents' economic power rather than their own efforts, it can be seen that achievementism is collapsing and the society is moving toward a fixed class. The current economic and social environment is not optimistic. Because the conditions of staying in their parents' house were entirely based on their parents' stable economic conditions, they were able to stay in their parents' house without being independent. However, in case of economic difficulties, the living base of parasite singles is likely to collapse significantly. Therefore, it is an important task to prepare their foundation for independence in order to be able to face difficult situations confidently.

Since this study targeted highly educated office workers with a college degree or higher working at the headquarters of a large corporation located in Seoul, there is a limit to generalization nationwide. For follow-up research, a nationwide study is requested. There is a need for a study comparing the lifestyles of parasite single singles and their thoughts on self-reliance with people with various occupations and educational levels. In this study, although the research was conducted based on a questionnaire survey, in-depth interview studies and case studies are required among parasite singles and their parents.

\section{References}

[1] Marriage and Divorce Statistics in 2020, Statistics Korea, (2021)

[2] National Survey on Fertility and Family Health and Welfare, Korea Institute for Health and Social Affairs, (2018)

[3] J. Y. Lee, A Study on the Reality and Prospect About Unmarried Single Males and Females, Women's Studies Center Mokpo National University, (2000), pp.125-143.

[4] J. H. Lee, A Study on the Continuation Process of Never-Married State on the side of Never-Married Men in their 40's, Korea Counseling Graduate University, Mater Thesis, (2015), pp.1-181.

[5] H. Y. Jeon, Reaearch of the Determinants in Marriage of the Youth, Seoul National University, Master Thesis, (2015), pp.1-86.

[6] E. S. Jeong, Impact of Views on Marriage and Tendency to Delay Marriage on Childbearing Intention of Single Company Employees, Sookmyung Women's University, Master Tehsis, (2015), pp.1-99.

[7] R. Y. Kim, Economic and Social variable on the Marriage Age, Korea University, Masrer Thesis, (2013), pp.1-8. 
[8] S. A. Park, Analysis of Main Causes and Processes of the Postponement of Marriage by Unmarried People at a Late Age using Grounded Theory, University of Ulsan, Master Thesis, (2013), pp.1-102.

[9] J. E. Lee, An Intergrated Study on Determinants of Marriage Intentions among Unmarried Women, Pyeongtaek University, Doctoral Dissertation, (2017), pp.1-81.

[10] Y. B. Lee, Y. W. Lee, H. J. Choi, H. Y. Lee, An Explorative Study on Coresident Adult Children in Korea, Korean Journal of Family Social Work, (2011), No.31, pp.5-30, DOI: http://doi.org/10.16975/kjfsw.2011..31.001

[11] J. P. Lee, Increasing Parasitic Singles Economic Decline: Lessons from Japan's Parasitic Singles Growth, Weekely Economy, (2009), Vol.614, pp.21-29.

[12] J. Curtin, Parasite singles in the international context, Social Trends, GLOCOM Platform, (2003)

[13] W. S. Aquilino, Two views of one relationship : Comparing parents' and young adult Children's reports of the quality of intergenerational relations, Journal of Marriage and the Family, (2002), Vol.61, No.4, pp.858-870, DOI: http://doi.org/ 10.2307/354008

[14] B. A. Mitchell, E. M. Gee, Boomerang kids and midlife parental marital satisfactions, Family Relations, (2004), Vol.45, No.4, pp.442-448, DOI: http://doi.org/10.2307/585174 